\title{
Hygric parameters of cement-lime plasters modified by superabsorbent polymers
}

\author{
Jan Kočí ${ }^{1, *}$, Akbota Begaly ${ }^{1}$, and Jan Forrt ${ }^{1}$ \\ ${ }^{1}$ Department of Materials Engineering and Chemistry, Faculty of Civil Engineering, Czech Technical \\ University in Prague, Thákurova 7, 16629 Prague, Czech Republic
}

\begin{abstract}
Moisture level significantly affects durability of constructions, their thermal performance and quality of indoor air. As the building envelopes are subjected to the effect of changing weather conditions from the exterior and numerous sources of water vapor from interior, the proper design may significantly increase the performance of the construction. In this paper, modified plasters with different amount of super absorbent polymers (SAP) are analyzed in the laboratory conditions in terms of their hygric and mechanical properties. The results showed that addition of SAP in the plasters may be promising for the utilization in building envelopes composition. However, the exact amount of SAP is crucial as the results revealed that if more that $1 \%$ of SAP is added to the plasters, the poor mechanical properties may exclude the plasters from real applications.
\end{abstract}

\section{Introduction}

The relative humidity of the indoor environment has impact on operational energy [1], internal comfort levels [2], and health of the occupants [3]. Therefore, regulating the relative humidity during building's service live is of high importance. Among the approaches for relative humidity controlling, the passive methods using novel materials seem very promising. The passive controlling is based on utilization of materials with good moisture adsorption/absorption capability in the composition of building components, which can uptake moisture from the air when its relative humidity increases and release moisture when the relative humidity drops [4]. Maintaining the relative humidity between 40 and $60 \%$ is beneficial to minimize health risks and discomfort [5].

The passive measures are mostly based on modulation of porous space of cement-based materials or adding absorbents/adsorbents in order to increase their buffering effect. Several materials has been investigated for that purpose and also several studies have been written on this topic, e.g. [6,7]. The additives are mostly represented by vermiculite, perlite, nano$\mathrm{TiO}_{2}$ or superabsorbent polymers (SAP) [8].

Utilization of SAP in cement-based materials is based on the ability of SAP particles to absorb large amount of liquids without dissolution. This phenomenon determines SAP for extensive industrial applications. For example, as denoted by Jensen and Hansen [9], SAP can be used as alternative to the internal curing agent in order to prevent the material from

*Corresponding author: jan.koci@,fsv.cvut.cz 
self-desiccation, avoiding crack formation. SAP can also improve mechanical properties [10], durability [11] or buffering capabilities [12] to control indoor environment of buildings [13].

In the proposed paper, the newly developed plasters with enhanced moisture accumulation capability are analyzed in terms of their hygric and mechanical properties. Namely, three different mixtures were tested with various amount of SAP additives $(0.5$, 1.0 and $1.5 \mathrm{wt} . \%)$. First, the fresh plaster mixtures were prepared and their workability was analyzed by flow table measurement in order to obtain an optimal water-plaster ratios. Then, basic physical and mechanical properties of hardened mortars were determined. Finally, several tests were performed in order to obtain water vapor and liquid moisture transport properties. The objective of the research is to obtain materials data, which will be used in the further stage of plaster development, for example as input parameters in numerical simulations.

\section{Experimental}

\subsection{Materials}

The investigation of material properties was done on four different of cement-lime plasters with various amount of SAP in the mixture. First plaster, marked as a reference plaster (RCP), was compared with three other cement lime plasters (SCP-0.5, SCP-1.0, SCP-1.5) that contained SAP polymers CABLOC CT provided by company Falconry s.r.o. The characteristics of SAP is shown in Table 1.

Table 1. Basic properties of applied SAP

\begin{tabular}{|l|c|}
\hline \multicolumn{1}{|c|}{ Property } & Value \\
\hline Bulk density $\left(\mathrm{kg} \cdot \mathrm{m}^{-3}\right)$ & 690 \\
\hline Moisture content (wt. \%) & 2.70 \\
\hline Particles over $300 \mu \mathrm{m}($ wt. \%) & 9.00 \\
\hline Particles $<200 \mu \mathrm{m}($ wt. \%) & 34.60 \\
\hline Particles $<100 \mu \mathrm{m}($ wt. \%) & 1.00 \\
\hline
\end{tabular}

For the modification, the cement-lime plaster MV-1 produced by company Knauf was selected. Basic properties provided by producer [14] are shown in Table 2.

The amount of water in the tested plasters was optimized by flow table tests according to ČSN EN 1015-3 [15] in order to ensure the same workability of fresh mixtures as for reference plaster. Based on the results of flow table tests the plaster formulas were set as shown in Table 3. Here, w/p (-) is the ration of the weight of water to the weight of plaster used in the plaster mix. 
Table 2. Basic properties of cement lime plaster

\begin{tabular}{|l|c|}
\hline \multicolumn{1}{|c|}{ Property } & Value \\
\hline Bulk density in dry state $\left(\mathrm{kg} \cdot \mathrm{m}^{-3}\right)$ & $1400-1600$ \\
\hline Water vapor diffusion resistance factor $(-)$ & $15 / 35$ \\
\hline Thermal conductivity $\left(\mathrm{W} \cdot \mathrm{m}^{-1} \cdot \mathrm{K}^{-1}\right)$ & 0.61 \\
\hline
\end{tabular}

Table 3. Composition of tested plasters

\begin{tabular}{|l|c|c|c|}
\hline Mixture & Plaster (kg) & SAP (g) & $\mathbf{w} / \mathbf{p ~ ( - )}$ \\
\hline RCP & 1 & 0 & 0.160 \\
\hline SCP-0.5 & 1 & 5 & 0.192 \\
\hline SCP-1.0 & 1 & 10 & 0.245 \\
\hline SCP-1.5 & 1 & 15 & 0.299 \\
\hline
\end{tabular}

\subsection{Methods}

Basic physical properties were determined from 10 specimens of each material having dimensions $40 / 40 / 10 \mathrm{~mm}$. The bulk density $\rho_{v}\left(\mathrm{~kg} \cdot \mathrm{m}^{-3}\right)$ of studied plasters was determined by dimensioning and weighting of dry samples. Matrix density $\rho_{\text {mat }}\left(\mathrm{kg} \cdot \mathrm{m}^{-3}\right)$ and open porosity $\psi\left(\mathrm{m}^{3} \cdot \mathrm{m}^{-3}\right)$ were obtained using the vacuum water saturation method [16]. The method is based on the concept of Archimedes mass, where the dried samples are immersed in desiccator with de-aired water. In the next three hours after sample immersing, the air is evacuated using vacuum pump and the specimens are left in the water for another 48 hours. The open porosity and matrix density are calculated from known massed of dry sample $m_{d}$ $(\mathrm{kg})$ and saturated sample $m_{w}(\mathrm{~kg})$ using the following formulas:.

$$
\begin{aligned}
& \psi=\frac{m_{w}-m_{d}}{V \rho_{w}}, \\
& \rho_{\text {mat }}=\frac{m_{d}}{(1-\psi) V},
\end{aligned}
$$

where $V\left(\mathrm{~m}^{3}\right)$ is the sample volume and $\rho \mathrm{w}\left(\mathrm{kg} \cdot \mathrm{m}^{-3}\right)$ is the density of water.

Mechanical properties were represented by compressive and flexural strength. For that purpose, 40/40/160 $\mathrm{mm}$ specimens were prepared. The determination of compressive strength was done using the DSM 2500 device.

The liquid moisture properties were investigated by means of water sorptivity measurement providing water absorption coefficient and apparent moisture diffusivity. The water vapor transport and storage properties were characterized by water vapor diffusion resistance factor. For the measurements, following samples were prepared: 10 cylindrical specimens with diameter of $105 \mathrm{~mm}$ and thickness $20 \mathrm{~mm}$ for water diffusion experiments and 5 specimens of $50 / 50 / 20 \mathrm{~mm}$ for water sorptivity tests. 
The water sorptivity was measured on samples that were water- and water-vapor proof insulated on four lateral sides. Then, the samples were immersed 1-2 mm in water tank, where the level of water were kept constant by a Marriotte's bottle with two capillary tubes. The mass of the specimens was recorded using automatic balance and the water absorption coefficient $A\left(\mathrm{~kg} \cdot \mathrm{m}^{-2} \cdot \mathrm{s}^{-1 / 2}\right)$ was then calculated as

$$
A=\frac{i}{\sqrt{t}}
$$

where $i\left(\mathrm{~kg} \cdot \mathrm{m}^{-2}\right)$ is the cumulative water absorption, and $t(\mathrm{~s})$ is the time from the beginning of the mass measurement.

The water vapor diffusion resistance factor was measured using cup method [16]. The measurement was based on one-dimensional water vapor diffusion through a sample. The diffusion water vapor flux was initialized by a difference between partial water vapor pressure in the air under and above specific specimen surface. Both water vapor flux and partial pressures were recorded during the measurement. In the experiment, The setup for wet-cup method was used. The method was defined by $95 \%$ and $50 \%$ of relative humidity above and under the sample. The water vapor diffusion permeability $\delta$ (s) was calculated from measured data according to the equation

$$
\delta=\frac{\Delta m \cdot d}{S \cdot \tau \cdot \Delta p_{p}}
$$

where $\Delta m(\mathrm{~kg})$ is the amount of water vapor diffused through the sample, $d(\mathrm{~m})$ is the sample thickness, $S\left(\mathrm{~m}^{2}\right)$ is the specimen surface, $\tau(\mathrm{s})$ is the period of time corresponding to the transport of mass of water vapor $\Delta m$, and $\Delta p_{p}(\mathrm{~Pa})$ is the difference between partial water vapor pressure in the air under and above specific specimen surface. Once $\delta$ was known, the other parameters, such as the water vapor diffusion coefficient $D\left(\mathrm{~m}^{2} \cdot \mathrm{s}^{-1}\right)$ and water vapor diffusion resistance factor $\mu(-)$, were calculated as

$$
\begin{aligned}
& D=\delta \frac{R T}{M}, \\
& \mu=\frac{D_{a}}{D},
\end{aligned}
$$

where $R\left(\mathrm{~J} \cdot \mathrm{K}^{-1} \cdot \mathrm{mol}^{-1}\right)$ is the universal gas constant, $M\left(\mathrm{~kg} \cdot \mathrm{mol}^{-1}\right)$ is the molar mass of water, $T(\mathrm{~K})$ is the absolute temperature, and $D_{a}\left(\mathrm{~m}^{2} \cdot \mathrm{s}^{-1}\right)$ the diffusion coefficient of water vapor in the air.

\section{Results and discussion}

Table 4. Basic physical properties of tested plasters

\begin{tabular}{|l|c|c|c|}
\hline Mixture & $\begin{array}{c}\text { Bulk density } \\
\left(\mathbf{k g} \cdot \mathbf{m}^{-3}\right)\end{array}$ & $\begin{array}{c}\text { Matrix density } \\
\left(\mathbf{k g} \cdot \mathbf{m}^{-3}\right)\end{array}$ & $\begin{array}{c}\text { Total open } \\
\text { porosity (\%) }\end{array}$ \\
\hline RCP & 1579 & 2574 & 37.96 \\
\hline SCP-0.5 & 1482 & 2557 & 42.04 \\
\hline SCP-1.0 & 1420 & 2541 & 44.12 \\
\hline SCP-1.5 & 1284 & 2550 & 49.65 \\
\hline
\end{tabular}

The obtained results are shown in the following section. The basic physical and mechanical properties are shown in Table 4 and 5 , respectively. The studied hygric 
properties, namely water vapor diffusion resistance factor and water absorption coefficient are shown in Table 6.

Table 5. Basic mechanical properties of tested plasters

\begin{tabular}{|l|c|c|}
\hline Mixture & $\begin{array}{c}\text { Compressive strength } \\
\text { (MPa) }\end{array}$ & $\begin{array}{c}\text { Flexural strength } \\
\text { (MPa) }\end{array}$ \\
\hline RCP & 3.87 & 1.76 \\
\hline SCP-0.5 & 3.74 & 1.96 \\
\hline SCP-1.0 & 3.59 & 1.84 \\
\hline SCP-1.5 & 2.91 & 1.45 \\
\hline
\end{tabular}

Table 6. Selected hygric properties of tested plasters

\begin{tabular}{|l|c|c|c|c|}
\hline Mixture & $\begin{array}{c}\text { Water vapor } \\
\text { diffusion } \\
\text { permeability }(\mathbf{s})\end{array}$ & $\begin{array}{c}\text { Water vapor } \\
\text { diffusion } \\
\text { coefficient } \\
\left.\mathbf{( m}^{2} \cdot \mathbf{s}^{-1}\right)\end{array}$ & $\begin{array}{c}\text { Water vapor } \\
\text { diffusion } \\
\text { resistance } \\
\text { factor }(-)\end{array}$ & $\begin{array}{c}\text { Water } \\
\text { absorption } \\
\text { coefficient } \\
\left(\mathbf{k g}^{-2} \mathbf{~ m}^{-2} \cdot \mathbf{s}^{-1 / 2}\right)\end{array}$ \\
\hline RCP & $1.155 \cdot 10^{-11}$ & $1.563 \cdot 10^{-6}$ & 15.8 & 0.0798 \\
\hline SCP-0.5 & $1.276 \cdot 10^{-11}$ & $1.737 \cdot 10^{-6}$ & 14.3 & 0.1369 \\
\hline SCP-1.0 & $1.483 \cdot 10^{-11}$ & $2.008 \cdot 10^{-6}$ & 12.7 & 0.1875 \\
\hline SCP-1.5 & $1.941 \cdot 10^{-11}$ & $2.628 \cdot 10^{-6}$ & 9.4 & 0.2547 \\
\hline
\end{tabular}

The presented resutls clearly show that increasing amount of SAP in the plasture mixtures significantly affects studied properties. The strnegth is generally decreasing, however, the flexural strength exhibited slight increase with addition of $0.5 \%$ and $1.0 \%$ of SAP, respectively. Addition of $1.0 \%$ SAP (SCP-1.0) resulted in decrease of compressive strength by $7.3 \%$ and increase of flexural strength by $4.5 \%$, which seems as the most suitable solution.

As for the hygric properties, the presence of SAP in the plaster composition resulted in increase of water and water vapor transport capabilities of all studied plasters. There is an general rule apparent - the more SAP in the plaster recipe, the more permeable the plaster become. Best results were therefore achieved for SCP-1.5, where the water vapor diffusion resistance factor decreased by $40 \%$ and water absorption coefficient increased by $320 \%$. Speaking about optimal solution from strength testing (SCP-1.0), the water vapor diffusion resistance factor decreased by $20 \%$ and water absorption coefficient increased by $235 \%$.

\section{Conclusions}

Several newly developed plasters with enhanced moisture accumulation capability were analyzed in terms of their hygric and mechanical properties. Addition of SAP in various amounts affected the compressive strength, which was decreasing with increasing amount 
of SAP. The flexular strength was first slightly increasing with increasing amount of SAP, however, when the amount of SAP exceeded $1.0 \%$, the flexular strength decreased rapidly. The hygric properties were affected by addition of SAP in the positive way, as both water vapor resistance diffusion factor and water absorption coefficient were improved. It can be concluded that the optimal plaster mixture is SCP-1.0, where the water vapor diffusion resistance factor decreased by $20 \%$ and water absorption coefficient increased by $235 \%$, while compressive strength decresaed by $7.3 \%$ and flexular stenght increased by $4.5 \%$. The result presented in this paper revealed high potential of studied plaster modifed by SAP, which will be further investigated within the frame of this project.

This research has been supported by the Czech Science Foundation, under project No. 18-03997S.

\section{References}

1. O.F. Osanyintola, C.J. Simonson, Energ Buildings 38, 1270-82 (2006)

2. L. Fang, G. Clausen, P.O. Fanger, Indoor Air 8, 80-90 (1998)

3. W.J. Fisk, Q. Lei-Gomez, M.J. Mendell, Indoor Air 17, 284-96 (2007)

4. R.E. Diasty, P. Fazio, I. Budaiwi, Energ Buildings 19, 61-73 (1992)

5. C. Rode et al., Moisture Buffering of Building Materials (Technical University of Denmark, Lyngby, 2005)

6. Y. He, X. Zhang, Y. Zhang, Energ Buildings 85, 506-14 (2014)

7. A.J. Klemm, K.S. Sikora, Constr Build Mater 49, 134-43 (2013)

8. L. Senff, G. Ascensao, D. Hotza, V.M. Ferreira, J.A. Labrincha, Energ Buildings 127, 980-90 (2016)

9. O.M. Jensen, P.F. Hansen, Cement Concrete Res 31, 647-54 (2010)

10. M.T. Hasholt, O.M. Jensen, K. Kovler, S. Zhutovsky, Constr Build Mater 31, 226-30 (2012)

11. A. Pourjavadi, S.M. Fakoorpoor, A. Khaloo, P. Hosseini, Materials and Design 42, 94$101(2012)$

12. J. Vieira, L. Senff, H. Gonçalves, L. Silva, V.M. Ferreira, J.A. Labrincha, Energ Buildings 70, 224-36 (2014)

13. H. Gonçalves, B. Gonçalves, L. Silva, N. Vieira, F: Raupp-Pereira, Energ Buildings $74,61-8$ (2014)

14. Knauf. Declaration of properties No. 0106_MV_1_2018_05_01, Prague, 2018.

15. ČSN EN 1015-3. Methods of test for mortar masonry - Part 3: Determination of consistence of fresh mortar (Czech Office for Standards, Metrology and Testing, Prague, 2000)

16. S. Roels, J. Carmeliet, H. Hens, O. Adan, H. Brocken, R. Černý et al., J Therm Envelope Build Sci 27, 307-325 (2004) 